\title{
Isso tudo é um grande baile Narrativa de jogos de cenas performados por/ com crianças do Ensino Fundamental I
}

Francis Roberta de Jesus ${ }^{2}$

\begin{abstract}
Resumo: O presente artigo comunica um percurso de problematização indisciplinar de práticas socioculturais por/com crianças de uma turma de 4o ano do Ensino Fundamental I, no ano de 2010, na Rede Municipal de Vinhedo (SP). As orientações dos caminhos trilhados e da forma de ver, compreender e empreender a educação em contexto escolar tiveram forte inspiração na filosofia de Ludwig Wittgenstein, bem como em outros autores filiados a correntes de práticas pós-modernas. O citado percurso é visto como possibilidade de problematização das relações estabelecidas entre matemática e arte em contexto escolar e como modo de transgressão da condição disciplinar desses campos de conhecimento.
\end{abstract}

Palavras-chave: Indisciplina; Anos iniciais do Ensino Fundamental; Geometria.

\section{This is all a big ball Narrative scenes games performed by/ with children of elementary school}

\begin{abstract}
This article reports a problematizing indisciplinary path of socio-cultural practices by/ with children in a school organization in the metropolitan region of Campinas, in Vinhedo city, in the countryside of the State of São Paulo in current fourth grade of elementary school during the 2010 school year. The guidelines of the pathways and the way to see, understand and undertake the educational context in education was strongly inspired by the philosophy of Ludwig Wittgenstein and other authors affiliated with currents of post-modern practices. The course mentioned is seen as a possibility for problematizing the relations between mathematics and art in schools and transgression so the disciplinary condition of these knowledge areas.
\end{abstract}

Keywords: Indiscipline; Early years of Elementary School; Geometry.

1 Afirmação de Ismael Ivo, diretor, bailarino, coreógrafo, intérprete e curador, criador do Impuls Tanz - Vienna International Dance Festival (1984) e responsável pela direção do festival de dança da Bienal de Veneza. Proferiu a citada afirmação ao ser inquirido sobre o que é linguagem. E resolve: "Isso tudo é um grande baile ..., movimento, pulsão, criação” (Bogéa, 2012). Trazemos essa descrição gramatical da linguagem para o percurso narrado à frente, no artigo, pois seria uma réplica semelhante a esta que proferiríamos, ao sermos questionados acerca do percurso vivenciado com 28 crianças de uma turma de quarto ano do Ensino Fundamental, no ano de 2010, numa escola municipal da cidade de Vinhedo (SP), na condição de professora polivalente da turma. A perspectiva de problematização indisciplinar apresentada nas cenas narradas encontrou continuidade nas turmas seguintes até a atualidade, porém, a turma referida é tomada como exemplo, dada a oportunidade de realização da pesquisa de doutorado de Jesus (2015), onde é possível conhecer o trabalho vivenciado de forma mais ampliada.

2 Doutora em Educação pela Faculdade de Educação da Universidade Estadual de Campinas - Unicamp. 
canto curto e insistente, entrecortado, que ela conhecia tão bem o significado .... Com o terceiro braço, alcançou a cítara. Involuntariamente, dedilhou as cordas e um som cristalino molhou o silêncio da madrugada com os acordes de uma melodia improvisada ${ }^{3}$.

Dentre as narrativas dos Vedas, antigas escrituras indianas reconhecidas como unidades e diversidades de distintas correntes hinduístas (Santoro \& Sartorelli, 2008), se encontra a de Saraswati. Muitas vezes classificada como fábula, enreda a forma como, pelo canto e encanto da deusa, as coisas foram criadas. "Saber é poder", ensinam as escrituras, que inscrevem na figura de Saraswati um histórico personificador de variadas formas de conhecimento: artes e práticas do espírito, relacionando sabedoria, razão, criatividade e pureza divina, além de atribuir-lhe a autoria da beleza, do primeiro alfabeto, da matemática, das ciências e da magia. $\mathrm{O}$ Gayatri Mantra, a ela dedicado, expressa: "possa inspirar nossas mentes..., doadora de conhecimento que destrói a ignorância” (Zimmer, 1998, p.145). Teria Saraswati se unido a Brahma e dividido uma porção de seu poder com a humanidade, sendo dela a responsabilidade de tutoria dos ofícios dos loquazes discursadores, de poetas, escritores, músicos, pintores, que constituiria inspiração sobre tudo quanto se move, explicando a origem da racionalidade, da pureza, da criatividade e dos conhecimentos.

\section{Pas de deux: arte e matemática}

Longe do anseio por uma noção de continuidade ou de totalidade em relação aos conhecimentos, chamamos a atenção para a imagem de Saraswati em função dos significados a ela atribuídos no que diz respeito aos conceitos de arte e de matemática. Nossa questão em relação a esses usos está direcionada ao sentido de como esses termos, muitas vezes vistos como opostos, são valorizados diferentemente, inclusive como estratégias de práticas de poder, em que um conhecimento é hierarquicamente posicionado em relação ao outro, como se um fosse dado à razão, e o outro, às paixões. Contudo, na narrativa hindu, parece não haver essa cisão entre ciência e arte ou, ainda, entre formas de linguagem, uma vez que se fazem presentes numa mesma deidade, de forma não concorrente e sem expressar os limites demarcatórios daquilo que defina ou explique o que vem a ser cada uma.

Entretanto, no campo das práticas educativas, a segmentação tem lugar fortemente demarcado. Não há dúvidas quanto à defesa humanística da importância da arte e da matemática para a formação humana e cidadã, erigindo a escola como

3 Recuperado em 28 de abril de 2015, de http://entremares.blogs.sapo.pt/18370.html 
espaço de contato com conhecimentos que hão de preparar o homem para inserção futura na sociedade e para o desempenho de práticas cidadãs, tal qual afirmam Silva e Galvão (2009, p.142). No caso, as autoras apontam para alguns usos do termo arte: técnica, expressão, atividade, conhecimento - usos relacionados a períodos historicamente marcados, partindo do jesuítico, alcançando os dias atuais e apontando uma crescente institucionalização das práticas artísticas, ao longo do percurso que segue, da Academia Imperial de Belas Artes, abarcado pelos movimentos da Escola Nova, das escolinhas de artes e das reformas educacionais.

Ao que nos parece, esse percurso da condição das artes no contexto educativo brasileiro passa pelas práticas sociais, em direção a uma crescente institucionalização, o que encontra expressão nas atualizações recentes da Lei de Diretrizes e Bases da Educação Nacional (LDB, 1996), ao apresentarem críticas de valorização da arte como forma de conhecimento e, a nosso ver, fortalecimento das barreiras que a categorizam e definem como disciplina. Assim, as práticas artísticas dentro da escola foram denominadas educação artística, a exemplo do texto da Lei 5.692/71 (LDB, 1971), e atividade educativa, posteriormente, como componente curricular obrigatório na educação básica, por meio da Lei 9.394 de 1996 (LDB, 1996, art. 26, $\S 2$ o). Por esse percurso de enrijecimento disciplinar, as artes são elevadas ao estatuto de conhecimento, e é feita distinção entre atividade e educação, apresentadas como modos diferentes de ver as práticas artísticas e seus lugares dentro da escola. Nesse ínterim, outros modos de ver tomam expressão, tais como as distinções dos usos do termo educação artística, seja no sentido de atividade educativa ou, ainda, no sentido de disciplina escolar.

Em relação à matemática, também apresenta formas de mobilização e usos disciplinares, nos contextos acadêmico e escolar. No caso deste último, é guardada como prática que apresenta, necessariamente, fundo lógico-racional. Dessa forma, seriam garantidos o aspecto e o espectro da neutralidade, seja ela considerada como linguagem, seja como ciência - das relações, das quantidades, das possibilidades, das construções, dentre outras -, expressa em definições da matemática como articulações do raciocínio lógico e abstrato, partindo de práticas axiomáticas e de argumentações pelas quais as formas lógicas válidas se fazem em garantia de conclusões verdadeiras - em relação a medidas, quantidades, espaços, variações, estatísticas e estruturas em formulações conjecturais, em busca de padrões. Esse percurso seria uma forma de penhor da cientificidade característica das práticas matemáticas, a fim de conduzir conhecimentos.

Segundo as reflexões de Chervel (1990) sobre a história das disciplinas escolares, os conteúdos de ensino possuem presença escolar recente, sob o interesse da vigilância relativa à boa ordem da educação. Àquilo que deveria preencher as práticas escolares deu-se o nome de disciplina, relativa à ordem que a educação 
deveria perseguir, bem como aos conteúdos a serem ensinados, modo de preservação de uma herança inventora de formas de vida que tornariam tais conteúdos necessários. Portanto, escolarização passou a ser necessidade, e aquilo que se ensina na escola, posto a serviço do imperativo disciplinar. Dessa maneira, vemos arte e matemática em contexto escolar como fontes de confusões conceituais, tendo em vista a alimentação de imagens fixas desses campos de conhecimentos, isto quer dizer, disciplinarizados. Ao relembrar a imagem de Saraswati, que seria narrativa de um início possível para as existências dessas práticas, teriam surgido, arte e matemática, de uma mesma extensão orgânica. Portanto, faria sentido a segmentação disciplinar?

\section{Glissade, entrechat, échappé: Outros modos de dançar}

Empregamos o termo práticas socioculturais como conjunto intencional e articulado de condutas individuais ou coletivas que constituem significações, em meio às atividades que compõem as práticas desempenhadas pelas pessoas que se engajam numa atividade humana, com propósitos compartilhados. A forma de existência dessas práticas é social, e a maneira de ver seus partilhamentos e suas intenções, seus valores, regras e intenções em suas realizações, é comunitária, de maneira a constituir diferentes comunidades de práticas, sempre influenciadas e condicionadas por instituições socialmente legitimadas (Miguel, 2010). Isso na perspectiva de que toda prática sociocultural seja produtora de cultura e no sentido de conceber as atividades humanas como formas abertas de organizações "e interações sociais constituídas por números não fixos de elementos interativos constituídos nessas atividades” (Miguel, 2010, p.10). “Assim, uma prática social é sempre cultural e uma prática cultural, sempre social” (p.12), uma vez que iteram rastros memorialísticos de conjuntos articulados de práticas socialmente produzidas, e esses conjuntos sempre são passíveis de significações.

Consideramos que Ludwig Wittgenstein pode ser aproximado dessa forma de ver as atividades humanas, pois acrescenta a elas a dimensão gramatical, tendo em vista que ele dá exemplos de jogos de linguagem em que palavras são empreendidas como ações carregadas de significados, cujas materialidades, inclusive, encontram lugar na materialidade dos corpos que desempenham ações regradas, constituintes de jogos de linguagem diversos, característicos de determinadas práticas socioculturais e formas de vida. Por esse modo de ver, a linguagem é praticada de modo que significados sejam constituídos de maneira diversa da dos modelos de fixações referenciais, axiomáticas e flexivas de definições, porém de acordo com contextos determinados (Wittgenstein, 2009, §15). Dessa forma, a prática da linguagem está intimamente relacionada aos seus contextos de produção, em que ganham 
importância tanto conhecimentos quanto gestos, instrumentos, ambientes e usos discursivos de termos gramaticais que enunciam sentidos, regimes de verdade, relações de poder e ações que necessariamente participam das dinâmicas situadas das práticas socioculturais. Portanto, é inaugurada uma possibilidade para ver os usos empreendidos e os movimentos constitutivos dos jogos de linguagem, aos quais Wittgenstein designa como totalidade formada pela linguagem e pelas atividades com as quais vem entrelaçada (Wittgenstein, 2009, §7).

Por essa razão, com a finalidade de ver os jogos de linguagem panoramicamente, faz sentido imaginá-los descompactados, fora do encapsulamento da economia disciplinar, por exemplo. Isso, pois, quando um termo passa a ser empregado de modo acostumado, fixo, e passa a produzir uma única forma de ver, a exemplo da disciplinaridade como forma de toda prática mobilizadora de cultura escolar - que parece ter vontades de estabelecimento de uma ordem da realidade, vontades de abstrações, vontades de produção e manutenção de um sujeito humano universal e de iterar rastros de uma ordem a priori ao entendimento e a toda e qualquer experiência -, ele - esse termo - pode ser visto como fonte de enganos, confusões conceituais provenientes de uma única forma de alimentação do modo de pensar e produzir formas de vida (Wittgenstein, 2009, §593). Entretanto, ao observar diferentes práticas, o emprego de um termo não apresentará um significado de uma vez por todas, porém, descreverá diferentes variações de sentidos, como no caso do empreendimento do termo "ter em mente”, que não designa necessariamente processos mentais, mas diferentes gramáticas de usos situados e não uniformemente referenciados (Wittgenstein, 2009, §33 e 592). Nisto, no ato de considerar casos particulares, residiria um valor terapêutico que não busca definições de conceitos fixos, mas seus deslocamentos possíveis. Isso é o que Wittgenstein pratica, ao variar exemplos de jogos de linguagem, como o da dor (§667), em que descreve modos como possíveis variações de uma dieta unilateral das doenças (\$255), de um único modo de pensar ( 33,38 e 132), expressam diferenças que formas habituais da linguagem não permitem compreender.

Àquelas confusões que seriam fontes de enfeitiçamento da compreensão e da linguagem, implicando, inclusive, em problemas filosóficos, Wittgenstein indica uma prática terapêutica de decomposição da fixidez de sentido e aplicação de um termo, com a finalidade de produzir outras formas de ver. No caso da matemática e da arte, ao observarmos usos desses termos em diferentes práticas, encontraremos adjetivações que iteram seus contextos e que podem ser entendidas "como uma manifestação de reconhecimento de outros jogos de linguagem” (Vilela, 2013, p. 219).

Compreendemos, portanto, que as formas de ver guardadas pela matemática e pela arte escolares e disciplinares são apenas um modo dentre os possíveis de praticá-las. E, imaginando formas de visão e de descompactação, pelos quais esses 
termos possam ser deslocados, participantes de contextos socioculturais em que assumam novos sentidos, intentamos que, ao problematizar os empregos desses termos, práticas, bem como produções de conhecimentos e de sentidos, também sejam problematizadas, podendo ampliar compreensões, operando em seus limites, o que desconstrói e transgride modos essencialistas de concebê-los. Assim, a estratégia terapêutica de Wittgenstein possibilitaria praticar e imaginar um modo distinto de visão, que seria a mobilização da matemática e da arte de modo indisciplinar, ao que Miguel (2010) denomina "problematização indisciplinar” e que implicaria em ver práticas artísticas e matemáticas mobilizadas em diferentes atividades humanas.

Se a terapia de problematização indisciplinar lida também com noções de translocalização, transculturação, transmodalidade, transtextualização; usos da linguagem como constituinte de múltiplos modos de comunicação semiótica; perpasse de signos por diferentes contextos, pensa significados como modos de interpretação que interagem com formas distintas de compreensão e produção de sentidos e de ver e praticar a linguagem. E implicaria uma maneira de praticar transformação nos modos de interpretação e de produção de significados (Pennycook, 2006, pp. 76-77), de forma que a noção disciplinar possa deslizar, à lembrança dos modos clássicos da dança, aos quais nomes como Vaslav Nijinski, Mary Wigman, Pina Bausch, Martha Graham, Kazuo Ohno, Twyla Tharpn, Merce Cunningham, Dimitris Papaioannou, Deborah Colker encenaram transgressões. E dançaram-nas. Isadora Duncan também: o descarte dos espartilhos, do collant, do tutu e das sapatilhas ressoou enredado por Gluck, Wagner e Chopin, na transgressão que se deu em forma de túnicas provocadoras da moralidade feminina da época. Praticou dança como experiência de movimento e movimentou uma forma de transgredir. Se pensar é transgredir como sugere Lya Luft (2005) -, dançar também o é, em musicalidade, dinamismo, expressividade de um corpo que não só pensa, mas se revela performaticamente em prática mestiça e nômade de investigação, de forma a alimentar a vontade de dançar distintamente, além dos paradigmas consagrados. Desse modo, sua transgressão desafiou tanto limites fundamentadores das categorias clássicas quanto os modos rígidos de praticar essa atividade. "Coreografias podem transportar, dividir, multiplicar o corpo de acordo com o critério e uso" (Derrida, citado em McDonald, 1982, p.74 [tradução nossa]) e criar coreografias incalculáveis, que nos incitam a afirmar que Duncan problematizou uma prática sociocultural e a deslizou para outros contextos de atividades: de modo semelhante, muitos outros artistas, além dos citados, foram movidos a exercer resistências à hegemonia de qualquer lógica na prática de conhecimentos compreendidos universalmente, porém situados em comunidades de práticas e formas de vida que compreendem determinados jogos de linguagem que, por sua vez, mobilizam conhecimentos, repetindo, performando, desviando, subvertendo-os. 
Nisso também residiriam forças ético-morais (McDonald, 2001) e políticas dos atos performativos ${ }^{4}$ por meio dos quais os percursos indisciplinares de problematização possibilitam modos outros, em que a linguagem performa, contrariando padrões de repetição social e culturalmente enraizados, considerando que a linguagem funciona do modo tal qual é praticada (Wittgenstein, 2009, § 83). Esses atos performativos possibilitam a visão das práticas cotidianas com desvios à prestação naturalizada, como necessária remissão a fundos referenciais. Os desvios permitem ver questões sociais, éticas, políticas, pessoais como relacionadas à efetivação de engajamentos performáticos em diferentes práticas, em que determinados conhecimentos são compartilhados, conforme necessidades para o desempenho efetivo da prática, conforme regras que a normatizam por critérios públicos de condições de verdade e de seus modos de legitimação.

\section{Nous dansons: problematização indisciplinar}

Por essa perspectiva, o indisciplinar e o transgressivo podem ser aproximados, afirmando propostas de problematizações de empreendimentos discursivos, gramaticais. Nesse sentido, o indisciplinar abriria espaço para imaginação de práticas escolares distintas daquelas impostas pelas organizações racional-disciplinares da arte e da matemática, num "sentido mais ilícito de atravessar fronteiras proibidas, mas, e talvez, no processo, começar a derrubar algumas dessas cercas disciplinares" (Pennycook, 2006, p. 73), o que, em sentido derridiano, seria "desconstrução"5.

Essa problematização indisciplinar, em seu aspecto terapêutico, realiza problematizações das práticas e dos usos característicos de jogos de linguagem com semelhanças de família, que remetem, por rastros analógicos, a outros jogos, negando não só a concepção de sujeito que se narra interiormente (estados mentais, consciência, representações, estruturas mentais, etc.), como também a construção de conceitos que estabilizem os usos (Jesus, 2015). Nisso se expressa uma perspectiva de educação escolar que tem por objetivo valorizar processos de problematização cultural e de práticas socioculturais.

Um exemplo será a narrativa que compreende o percurso trilhado com as crianças no ano de 2010. Ela expõe um fragmento diminuto do percurso terapêutico de

4 Considerando o sentido articulado por Judith Butler (1994), performatividade está compreendida como aspecto do discurso que, à maneira foucaultiana, seria meio de operação do poder e da produção do sujeito, ligado aos atos performativos de fala, que trazem à existência aquilo que nomeiam - referência à produção austiniana.

5 Desconstrução no sentido de analisar estruturas sedimentadas que formam os elementos discursivos; a forma da discursividade filosófica na qual pensamos; o que passa pela língua, pela cultura ocidental, pelo conjunto que define nosso pertencimento a essa história da filosofia, o que marca certa dívida relativa aos usos do termo "dissociação" por Freud e "destruição", por Heidegger, abarcando certa inflexão disso (Derrida, 2004). 
problematização indisciplinar construído naquele ano, em que as crianças da turma mobilizam conhecimentos diversos, que podem ser classificados como matemática ou arte; porém, sem esses limites reforçados. No caso, as ações empreendidas encenaram práticas e contextos constitutivamente inclusivos de atos e discursividades em que formas de organizações humanas de vida e suas variações são encenadas, para o que não é necessário dominar técnicas categorizadas como plásticas, artísticas ou teatrais, mas importa a linguagem em situação cotidiana, onde participam gestos ${ }^{6}$ e movimentos que também constituem contextos de criatividade, até mesmo criatividade transgressora, como no caso do Lay Theatre (Read, 1995), por exemplo. Dessa forma, contextos também atuam como forma de identidade performática e envolvem a compreensão das relações entre comunidades de prática, de forma a

6 A bailarina Marilene Martins é reconhecida por escrever movimentos por meio de gestos e palavras, como expressividade da dança moderna. O seu nome integra práticas históricas de transformações literárias, na dança, no design e nas artes plásticas, sendo sua produção de importante influência no percurso memorialístico da dança no Brasil. A noção do movimento em jogos de linguagem de diferentes contextos e que carregam semelhanças de família é interessante, pelo que mostra de formas constitutivas da linguagem nas ações empreendidas nas práticas socioculturais, de forma a comunicar éticas, valores e confusões conceituais: que é dança, que é linguagem, como criar movimentos com palavras? A linguagem não está fora dos jogos; contudo, não é postulada, mas performada em cada contexto, condição de sentido, que regulará o que pode ser dito e feito. Então movimentos podem ser empreendidos por gestos e palavras conforme os usos, assim como juízos éticos e estéticos. Se Marilene dança, inscrevendo gestos e palavras em movimentos, esse juízo possui sentidos de acordo com os jogos de linguagem em que a bailarina se inscreve e subverte, fora da compreensão isomórfica da linguagem como descrição de fatos, porém nas circunstâncias em que a linguagem é empreendida (Cunha, 2009). Da mesma forma, podemos afirmar que os sentidos atribuídos por Giorgione à representação de uma paisagem com figuras, às cores, à iluminação, às criações do chiaroscuro e do sfumato como forma de produção de um modo de ver profundidade numa tela, permitem tanto descrição dos sentidos, quanto deslocamentos a outros jogos em que esses termos e objetos assumem diferentes funções. Portanto, ao afirmar que Marilene dança daquela forma, não estamos empreendendo aspectos literários, descrições linguísticas ou geométricas, mas praticamos uma variação de aspecto da dança, do ato de dançar, das palavras e dos movimentos. Ela, de algum modo, dança; mas transgride as regras desse jogo, definidas, porém não determinantes de todas as formas possíveis de dançar; porém, todas elas carregam entre si rastros de semelhanças em que vemos empregos gramaticais e deles aprendemos dinâmicas de funcionamento. Assim, um "significado estaria no conjunto de usos que fazemos dos enunciados, e cada situação de seu emprego revelaria um aspecto, desse conjunto, a ele ligado por semelhanças de família.... Tudo se passa como numa espécie de inventário genealógico" (Cunha, 2009, p. 12). Portanto, para dançar não há um termo geral ou propriedade comum a todos os jogos que, de alguma forma empreendam o termo. Mas, como explicar a alguém o que significa compreender dança? E matemática? E arte? O indicativo que apontamos, pela inspiração teórica que nos traz Wittgenstein, são os usos. Para isso, os exemplos variados são necessários: coreografar, espectar, dançar, ver, ouvir, descrever dança, comportamentos de quem nela está inserido; assim como a pintura, a matemática, a música, a poesia, dependem de uma prática e da gramática que a orienta. Gestos, palavras, música, movimentos participam do jogo e, para nele se inserir, é preciso seguir regras, tornar-se hábil em desempenhar técnicas e mobilizar os conhecimentos necessários para o engajamento e a participação contributiva à prática em questão, ao invés do paradigma da aplicação ideal de uma regra, ou ainda, de ideais de precisar, como no caso, dançar. 
comparar saberes compartilhados cotidianamente ${ }^{7}$. Essa prática permite um exame crítico das relações entre escola, matemática, arte e vida cotidiana, de maneira a reproduzir uma noção de economia não de troca entre polos contextuais, mas, sim, de desenvolvimento da noção de expressão de relações constitutivas entre elas, atuando na poética das possibilidades de uma prática educativa que não pratique assepsia da vida e nem mesmo persiga o objetivo de controlar completamente suas possibilidades ${ }^{8}$.

Existem perspectivas que veem a relação arte-matemática, em que a arte atua como aplicação de princípios geométricos; ou, ainda, há aquelas que enxergam a geometria como aplicação no campo artístico: arte da geometria e geometria da arte. Por esses termos, citamos a geometria como modo característico de estabelecer relações entre matemática e arte no contexto escolar: "a arte aliada ao ensino da geometria" (Silva, 2005), o que também carrega ideia de arte e geometria como práticas autônomas e disjuntas. Esse aspecto não parece ter estado desde sempre presente naquela relação, uma vez que, em registros históricos - lembramos do trivium e do quadrivium e de práticas de povos antigos - pereciam manifestos em união, ao entender matemática e arte como manifestações da vida, à lembrança da conjunção presente na figura de Saraswati. Portanto, consideramos que a imagem da deusa desconstrói a noção disciplinar como dicotomia entre o intelecto e a emoção, a racionalidade e a subjetividade, a racionalidade e a sensibilidade, corpo e mente.

Mirian Celeste Martins, coordenadora de educação da 25a Bienal de Arte de São Paulo, afirma que a arte está dispersa nas mais simples formas de organização da vida (Bencini, 2002). No caso do evento, ao reunir arte contemporânea numa relação de perturbação e provocação do espectador em relação à vida, exerce forma de transgressão das normas estabelecidas. É o que parece ser a ocasião de Éder Oliveira, ao compor a musicalidade de seu ofício com lixadeiras, furadeiras, cortadeiras e serras que fizeram parte da composição artística do galpão da 31 a Bienal; ao problematizar a condição pós-moderna metropolitana, colorindo paredes externas em formas e

7 Aqui trazemos à lembrança a maneira com que Duchamp mobiliza a cotidianidade, sobretudo esculturalmente, ao deslocar elementos da vida corrente para o campo de atividade artístico. É possível compreender um processo de construção de sentidos, em que um objeto - por exemplo, presente em práticas de transporte de mercadorias, no caso, uma roda - é apresentado no ready made Roue de bicyclette (1913), em que é deslocado de seu uso privilegiado para o campo da arte. Dessa forma, problematiza uma definição de arte e da origem do uso de objetos na vida cotidiana, ou ainda, a vida cotidiana como arte; noções estéticas, valores, limites territoriais de campos de atividades, e produz estetização da vida cotidiana e forma de transgressão das categorias do entendimento, além da problematização apresentada entre a imagem produzida nas obras e os termos que as intitulam, entre as relações obra-espectador e espaço-obra.

8 “Uma poética do possível, imaginada por Richard Kearney" (Read, 1995). 
rostos. Essa problematização também passeou pelas formas representadas: homens amazônicos, caboclos e mestiços que, na retratística de Éder, ganham a expressão de um olhar que pergunta, com firmeza e candura: "Por que o temor? Questão de descontextualização das imagens que saem da página policial e vão para a página da cultura. Questão anônima”. Confronto, choque ${ }^{9}$, arte, vida, cultura, dispersos nas paisagens do cotidiano.

Considerando o artigo 32 da LDB (1996):

formação do cidadão mediante o desenvolvimento da capacidade de aprender, tendo como meios básicos o pleno domínio da leitura, da escrita e do cálculo e da compreensão do ambiente natural e social do sistema político, da tecnologia, das artes e dos valores em que se fundamenta a sociedade.

Seria este o propósito que mobiliza práticas que inserem a matemática na arte, ou, ainda, a arte na matemática? No limite do que possam realizar as definições que ministram lições de coisas cujas leis determinam: ou isto ou aquilo! Tem-se chuva e não se tem sol (Meireles, 1990), consideramos, porém, que existem ares de mudança e de transgressão. Quem os anuncia é Drummond (Andrade, 2012): "Isso é aquilo: o fácil e o fóssil, o míssil e o físsil, a arte e o enfarte, o ocre e o canopo”.

\section{Assemble, pas de valse: Baile en(cena)}

Ainda clamaria no deserto a voz que anseia por definição: que é arte? E matemática? ${ }^{10}$ Ofício do matemático, do artista, do esteta, do estatístico, do filósofo, das áreas de aplicação, das ciências exatas, das linguagens... Ocupar-se de uma definição seria determinar os limites da arte e da matemática, como coisas eternas, definitivas e com graus certos de generalidades, visão esta que conflita com aquela que toma as práticas socioculturais como unidades de problematização e vê arte e matemática como jogos de linguagem constitutivos de diferentes formas de vida

9 Éder Oliveira pratica um modo de intervenção nas paisagens metropolitanas, iniciada na capital paraense, a site specific (trabalho planejado que dialoga com o espaço para o qual a obra é elaborada). Vídeo-fonte recuperado em 7 de julho de 2015, de www.youtube.com/watch?list=PLkonCRbZ6HCeCuWj-OSMW8xo_KDYS6zwL\&v=BEAWJEAp2So

O jogo de definições também pode ver visto como contextual, como no caso de Renné Magritte, que produz uma série de obras em que problematiza jogos outros, como de referência e semelhança, em que as gravuras apresentam formas que parecem designar objetos aos quais se pode nomear ostensivamente - à semelhança do jogo desempenhado nas Confissões de Santo Agostinho - mas, que vêm acompanhados da inscrição com palavras negando serem o que, a princípio, numa visão generalizada e acostumada, parecem ser. Um exemplo é a gravura de 1964, intitulada Ceci n’est pas une pomme, onde está representado o que parece muito proximamente ser uma maçã, e a inscrição que dá nome à obra acompanha a imagem em sua parte superior. 
e práticas e que, portanto, dão-se e são praticados necessariamente vinculados ao contexto em que são desempenhados.

- O que quer dizer 'cativar'?

- A linguagem é uma fonte de mal-entendidos (Saint-Exupèry, 1989, p. 36).

A linguagem, diz a raposa, é fonte de mal-entendidos. Ela, então, passa a explicar ao Pequeno Príncipe o que é cativar. E o faz por meio de exemplos de práticas que expressem sentidos do que possa descrever o ato de cativar. Tratar matemática e arte daquela primeira maneira faria emergir um problema conceitual, um mal-entendido, como se a raposa desse um significado último de cativação. Mas a raposa dissolve esse problema, por uma abordagem que desloca sentidos e que, segundo Crespo (2008), teria sido praticada por Wittgenstein no caminho de seu Tratactus logico-philosophicus para as Investigações filosóficas, o que poderia ser estendido aos modos como o filósofo vê a matemática e a estética. Ao abordar e discutir concepções sobre imagem, expressão e percepção, por exemplo, num processo de transformação “da lógica em gramática, da imagem em aspecto, da representação em percepção, do eu em nós ou forma de vida" (Crespo, 2008, p.07), Wittgenstein aproxima a investigação filosófica da investigação estética, expressa ver tensões entre questões conceituais estéticas que são colocadas como oposição às científicas e, por uma terapia gramatical, alcança uma significação explicitada na afirmação da filosofia como poesia, o que poderia ser relacionado às diferentes formas de ver um modo não só de composição filosófica, como também do mundo, do homem, da arte, da percepção, da vontade, da compreensão, dentre outros aspectos das atividades humanas:

Aqui reside para nós o enorme perigo: querer fazer distinções sutis. É como querermos explicar o conceito de corpo físico a partir do que "realmente é visto"- [ênfase no original]. Deve-se antes assumir o jogo de linguagem cotidiano .... A título de exemplo, olhe com atenção os aspectos do triângulo. O triângulo pode ser visto: como buraco triangular, como corpo, como desenho geométrico; estando sobre sua linha fundamental, pendurado em sua ponta; como montanha, como cunha, como seta ou mostrador; como um corpo tombado, que (por exemplo) deveria estar sobre o cateto mais curto, como um paralelogramo pela metade, e diversas coisas mais. "Você pode pensar ora nisto ora naquilo, pode vê-lo, ora como isto, ora como aquilo e então você o verá ora deste modo ora de outro modo"- Mas como? Não há nenhuma outra determinação .... Eu creio que hábito e educação têm aqui um papel a desempenhar (Wittgenstein, 2009, pp. 257-259).

Ao se vivenciar uma prática social, não se trata de buscar explicar causas físicas ou psicológicas que determinem uma categoria de arte ou matemática no sujeito, 
porém a descrição de ações e expressões constituídas nessa atividade, não se tratando de enigmas de relações de causa e efeito, o que tem sentido no fluxo da vida (Crespo, 2008): audição de uma peça musical, designação de uma cor, nomenclatura de objetos, emprego dos números, leitura de um poema, percepção de formas empreendem domínios de técnicas, procedimentos, que não são predeterminações de um processo em que os significados estejam presentes não por determinações, mas por usos; em que a iterabilidade de signos performe funções de significados, implicando identidades e diferenças, o que não aprisionaria qualquer significado geral, mas orienta significados contextuais. Isto envolve aprendizagens de regras, técnicas e procedimentos aplicados a contextos de ação e experiência; então as razões e as compreensões se dão "no interior de um jogo. O encadeamento das razões chega a um fim e, na verdade, à fronteira do jogo" (Wittgenstein citado em Crespo, 2008, pp. 18-19). Essas razões coincidem com determinadas práticas socioculturais a elas intrínsecas.

Segundo Crespo (2008), Wittgenstein complementa essa forma de ver com modos de descrição de semelhanças de família entre atividades artísticas e filosóficas:

"A estranha semelhança entre uma investigação filosófica (talvez especialmente na matemática) e uma investigação estética. (Por exemplo: o que é que está mal neste vestido, como é que deveria ser, etc.)”

"As questões científicas podem interessar-me, mas nunca me agarram. Isso só mo fazem que questões conceptuais e estéticas. No fundo, a solução dos problemas científicos é-me indiferente, mas a de outros não o é". Duas coisas podem retirar-se dos aforismos: primeiro que são os problemas estéticos e conceptuais que agarram [fesseln] Wittgenstein e que só a solução desses problemas não lhe é indiferente. Este é um elemento importante, porque mesmo não se tratando de uma coincidência entre aquelas duas esferas, pode afirmar-se que o problema estético é um problema conceptual. E, dada a tal proximidade, então são os problemas conceptuais e estéticos que orientam o seu pensamento, a sua filosofia, a sua escrita. A forma mais clara de expressar a contaminação e possível semelhança entre as investigações estética e a filosófica é feita pelo próprio Wittgenstein quando escreve: "Penso ter resumido a minha atitude relativamente à filosofia quando disse: a filosofia só deveria poder ser poesia”. O problema aqui em causa diz respeito à determinação do valor filosófico que a matriz poética [ $d i$ chten] e os problemas das artes possuem. No modo como Wittgenstein compreende, e leva a cabo, a tarefa filosófica, a atividade poética (no seu mais amplo sentido) tem um valor metodológico e estilístico. Por outro lado, as afirmações de Wittgenstein permitem, primeiro, identificar e, depois, descrever o parentesco existente entre o modo como se pensa uma questão conceitual em filosofia e o modo como se pensam os problemas da arte [ênfase no original] (pp. 22-24). 
Isto, além do aforismo à descrição da linguagem em estado civil, não cabendo à filosofia solucionar confusões conceituais por meio de descobertas lógico-matemáticas, não deve tocar um uso real da linguagem, mas descrevê-lo (Wittgenstein, 2009, §124), fixar regras pelas quais nos enleamos num jogo, e "é este enlear-se nos jogos que queremos entender, isto é, queremos abarcá-lo com a vista... o estado civil da contradição, ou seu estado no mundo civil; este é o problema filosófico" (§125). Assim, não seria ofício da filosofia eliminar contradições de fundamentos conceituais científicos, como da matemática ou da arte, por exemplo, mas, para não deixar tudo como está (\$124), é preciso olhar para a linguagem em curso da forma tal qual a constituímos cotidianamente, no dia a dia, em que conceitos podem ser modificados e podem não funcionar tão bem quanto uma ideia anterior imaginada, ou tal qual a postulação de um fundo referencial. Os significados dar-se-ão nos usos, e tudo o que seja relevante para a filosofia não virá dos conceitos que produziria, por descobertas, para serem usados na vida comum. Entretanto, considerando que tudo esteja aberto, dado à vista, como sugere Wittgenstein, a filosofia não teria o que esclarecer ou desvelar, mas, sim, tomar o que está à vista de todos e publicado pelo uso regrado das palavras, uso que percorre gramáticas, as quais são seguidas, alteradas, criadas (§126). Portanto, seria tarefa da atividade filosófica conhecer essas orientações gramaticais. Dessa maneira, o estado civil das coisas seria em seus aspectos simples e triviais que acostumam o olhar e não chamam a atenção, mas que podem ser objetos de problematização terapêutica, pois estabelecem "uma ordem para uma finalidade determinada; uma das muitas possíveis; não a ordem" (Wittgenstein, 2009, §132).

Por este percurso, a terapia filosófica wittgensteiniana participa dos modos como se veem as coisas e daquilo que delas se espera, e, para cada caso, diferentes terapias podem ser praticadas, pois não há um problema de uma vez por todas, mas casos particulares a cada jogo de linguagem contextualmente situado.

Assim, entendemos que o olhar que Wittgenstein dirige à poesia pode ser empreendido à matemática, à lembrança da figura de Saraswati e à remissão ao interesse de relações comparativas, que permitam perceber que entre o filósofo, o matemático e o artista se podem estabelecer continuidades, descontinuidades e relações entre os diferentes jogos de linguagem, sem privilegiar um em detrimento do outro.

Analogias como essas permitem deslocamentos de um campo de atividade a outro, porém não aplicações necessárias de um sentido contextual a outro, o que caracterizaria um procedimento gramatical em que se observam diferentes atividades humanas e se estabelecem relações entre elas. Nisto estaria a realização do mote $I$ destroy, I destroy, I destroy, pelo qual Wittgenstein (citado em Crespo, 2008, pp. 29-30) caracteriza o caráter de sua prática filosófica, de busca por novos espaços, 
novos ares, sem estabelecer ideais ou necessidade de realocar nova metafísica em lugar daquelas que desconstrói. E essa desconstrução terapêutica pode ser fugaz e ver possibilidades em toda parte. Por isso, nos usos, uma proposição, uma interjeição, um gesto, um verso, um diverso, uma prosa, a métrica, as rimas, encontram lugares no funcionamento da linguagem e, dessa maneira, cada coisa passa a ser vista num espaço de possibilidades.

Num paralelo com a geometria, há condições de existência de determinados entes que passam a existir geometricamente, de acordo com as regras e com a estrutura lógico-geométrica que os determina. Disso incorre que o empreendimento do termo espaço, por exemplo, não determine a coincidência do espaço euclidiano com o visual, tendo em vista que uma ação desempenhada, em cada contexto, terá diferentes consequências:

no espaço euclidiano, errar na identificação de uma forma (por exemplo, confundir um quadrado com um retângulo) não tem consequências, mas errar no espaço visual (colocar um objeto no lugar errado, não saber designar o lugar onde está a nossa casa, não medir bem se o carro que queremos estacionar cabe no lugar que vemos, não saber dizer se se está aqui ou ali, etc.) tem consequências, não é indiferente. Mas mesmo havendo este abismo há uma correlação: o espaço geométrico possibilita a existência de coisas no espaço (Crespo, 2008, p.96).

No jogo da lógica formal, geometria é pautada como modelo de representações de objetos em determinado espaço. Por essa ótica, o mundo pode ser visto por meio de representações geométricas; uma maneira de a matemática sair de si própria, embora mantendo a mesma significação do campo de atividade que mobiliza conhecimentos estritamente matemáticos e, mais especificamente, geométricos, o que ainda pode ser denominado como práticas de transposição e de modelação. Essas permitem ver uma peça coreográfica, tal qual a Dínamo, de Déborah Colker (2006), como uma figuração em movimentos e funções de espaços topológicos, projetivos; e, assim, produzir uma forma de ver o mundo, a exemplo da axiomática de que se possa "traçar uma única reta ligando quaisquer dois pontos"11. Teria esse sistema de regras necessariamente sido seguido por Enrique Carbajal Sebastian, Gabriela Böer, Pablo Siquier, Cecília Biagini, Elon Cerqueira, Paulo Werneck, Lygia Clark, Inês Pimentel, Felipe Nuno, Jen Stark, Quim Alcântara, Amadeu de Souza Cardoso? Seria tudo isso geometria - ainda no caso de negar o quinto postulado euclidiano, ou ainda, desconstruí-lo -, um traço geral e universal das práticas artísticas que parecem se aproximar da rigidez axiomática do traço? Seria como que inquirir se o ballet seria o fundamento primeiro para toda e qualquer dança...

11 Referência ao primeiro postulado de Euclides. 
Espaço constituído por deslocamentos, kinesfera, eixos, dimensões, níveis e direções; relação entre o corpo e o ambiente no qual se dá. Então o baile assume nova coreografia: com a turma de quarto ano do Ensino Fundamental I, foram criados espaços aos quais denominamos rodas de problematização, surgidos a partir de uma perspectiva indisciplinar de organização de tempos ${ }^{12}$, espaços e movimentos dentro da escola. Como as crianças expressaram, ao início do ano, interesse por práticas de transporte de mercadorias, deslocamento e localização espaciais, práticas socioculturais, como estocagem, cartografias, produção de mercadorias, desenhos e peças artísticas, foram estudadas como produtos de pesquisas pelas crianças, propulsoras de provocações feitas pela professora. Também foram feitas unidades de problematização, reflexões e mobilização de conhecimentos.

Nesse breve contexto, na ocasião de uma roda em que uma aluna trouxera uma imagem de uma obra de Piet Mondrian - uma de suas composições de imagem bidimensional em azul, vermelho e amarelo -, ocorreu a discussão sobre o que seria necessário para produzir uma representação do percurso de cada criança de sua casa para a escola:

- Temos que fazer uma linha! (Davi)

Bianca trouxe uma imagem que recortou de um livro didático e apresentou à turma:

- Eu trouxe a foto de um quadro que está cheio de linhas. - E apresentou a imagem:

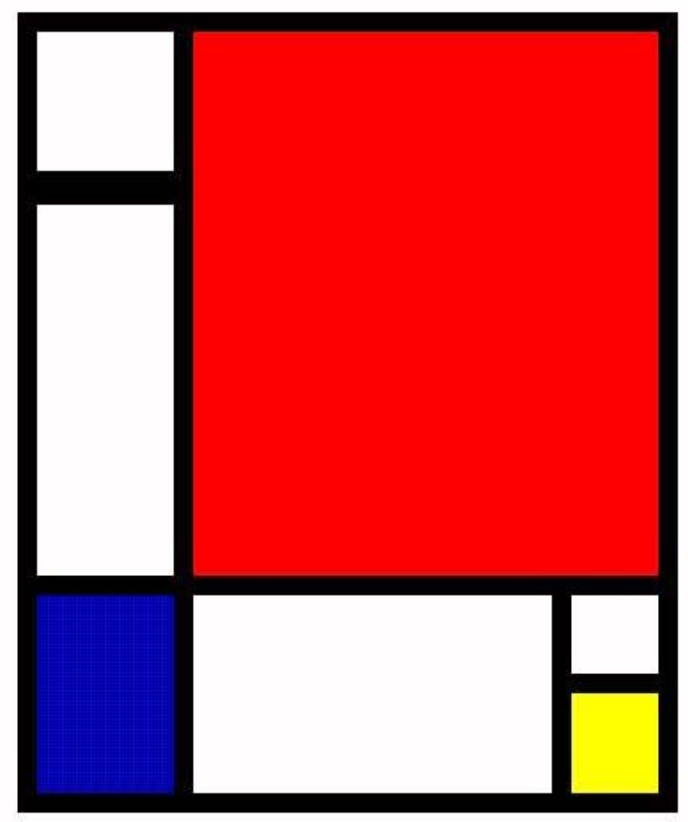

Figura 1: Mondrian - Azul, vermelho e amarelo (1930).

12 Lembrança da coreografia "Black and White" do balé Falling Angels e sua forma de desconstrução do tempo, baseada numa forma ritual cerimonial africana. 
A partir da apresentação da menina, a turma se engajou numa pesquisa acerca da vida do pintor e criou uma narrativa que dava razões para uma produção artística, aproximada do percurso de estudos que estavam realizando. Essa narrativa afirmou que Mondrian estudou as linhas e seus movimentos, o que estaria expresso em obras tais como A árvore cinza, Maçã florescer, Árvore em flor, Pier and ocean, dentre outras, às quais as crianças empreenderam um modo de ver:

“As linhas dançam!”. [Viram rastros de semelhanças e se engajaram, produzindo o que denominaram dança das linhas]. "Quando a gente contorna um objeto, as linhas vão mudando: tem vezes que são retas, para cima ou para baixo, se encontram, cumprimentam e dançam". "Tem assim também, ó" [demonstração diagonal com o braço] (Matheus). "Tem linhas que fazem ondas" (Joyce). "Tem vezes que elas se encontram e formam uma forma!" (Ryan). "Cada forma tem as linhas de cada lado" (Bianca). "Eu consigo fazer um círculo com uma linha só. O quadrado não. Mas se eu colocar uns preguinhos, dá para usar uma linha só de barbante pra fazer um quadrado. E agora?" (Aline). "Nessa forma aqui, todas as linhas são iguais. Olha o tamanho dos barbantes ... tudo igual” (Larissa).

Dessa maneira foram constituídos os percursos da turma, e por ela enfrentados problemas para os quais suas pesquisas traziam dissoluções: "E o círculo? A gente precisa de quantas linhas para formar um?" (Émerson). Tentando encontrar alguma explicação para essa problemática, uma das crianças usou barbante para circundar o cesto de lixo da sala, deixando o desenho formado sobre o chão e explicando que "não são muitas linhas, mas uma só", cujas pontas se juntam. Embora não tivessem feito distinção entre círculo e circunferência, a discussão pareceu estar em torno da equidistância de pontos sucessivos de um centro comum, o que Geovana teria expressado como "sem lados", designando a extensão da circunferência com uma linha única para construção, ao invés do aumento de números de lados poligonais:
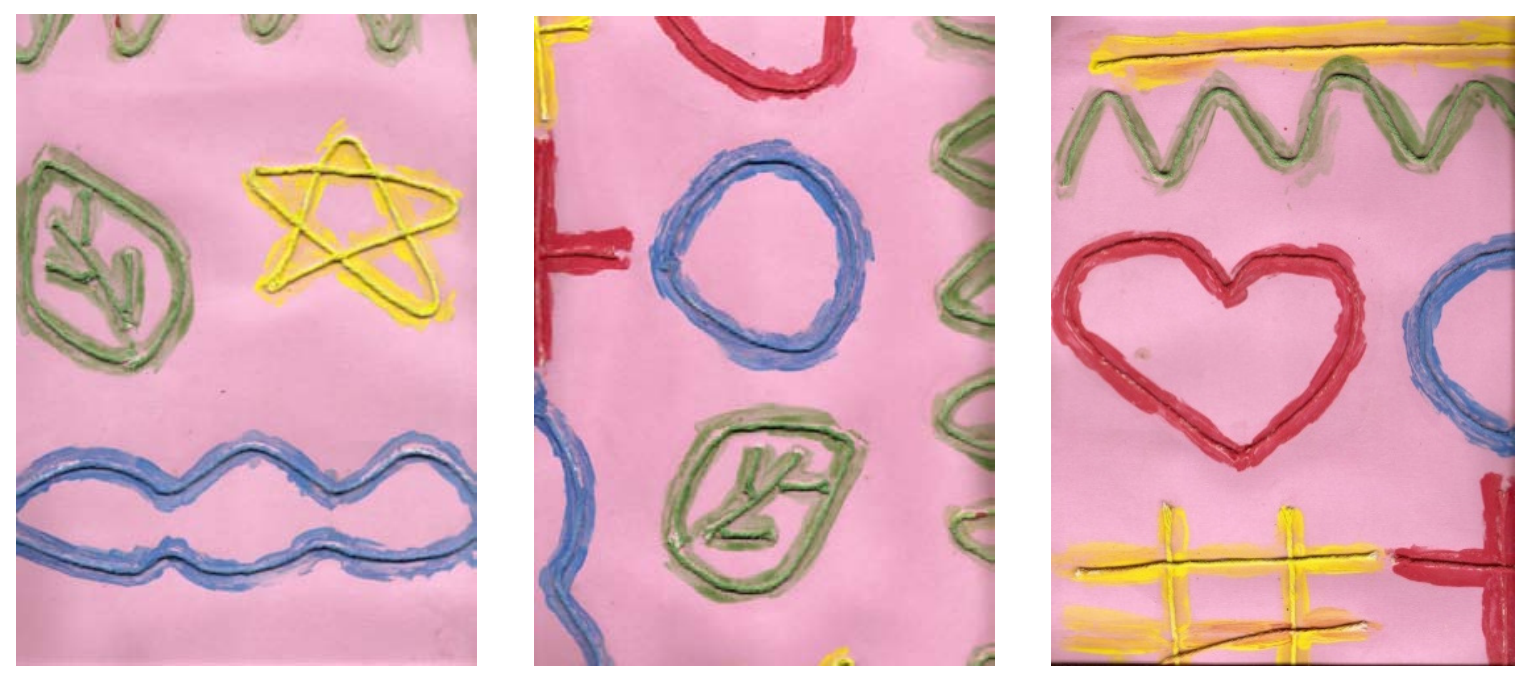

Figura 2: Imagem de uma das obras da exposição “Dança das linhas” (4º ano, 2010). 
A investigação prosseguiu em narrativas e ações performáticas das crianças, produzindo extensões de problematizações a várias atividades que envolviam seu cotidiano. Com as discussões realizadas nas rodas, passaram a colecionar imagens, vídeos, textos e objetos relacionados a diferentes campos de atividades, além da produção de Mondrian. Ryan apresentou uma imagem que, no aspecto espacial, mudaria a forma de compreensão da grande maioria dos colegas, o que foi relacionado à noção que constituíram de que "as linhas podem ser movimentadas e formar figuras".

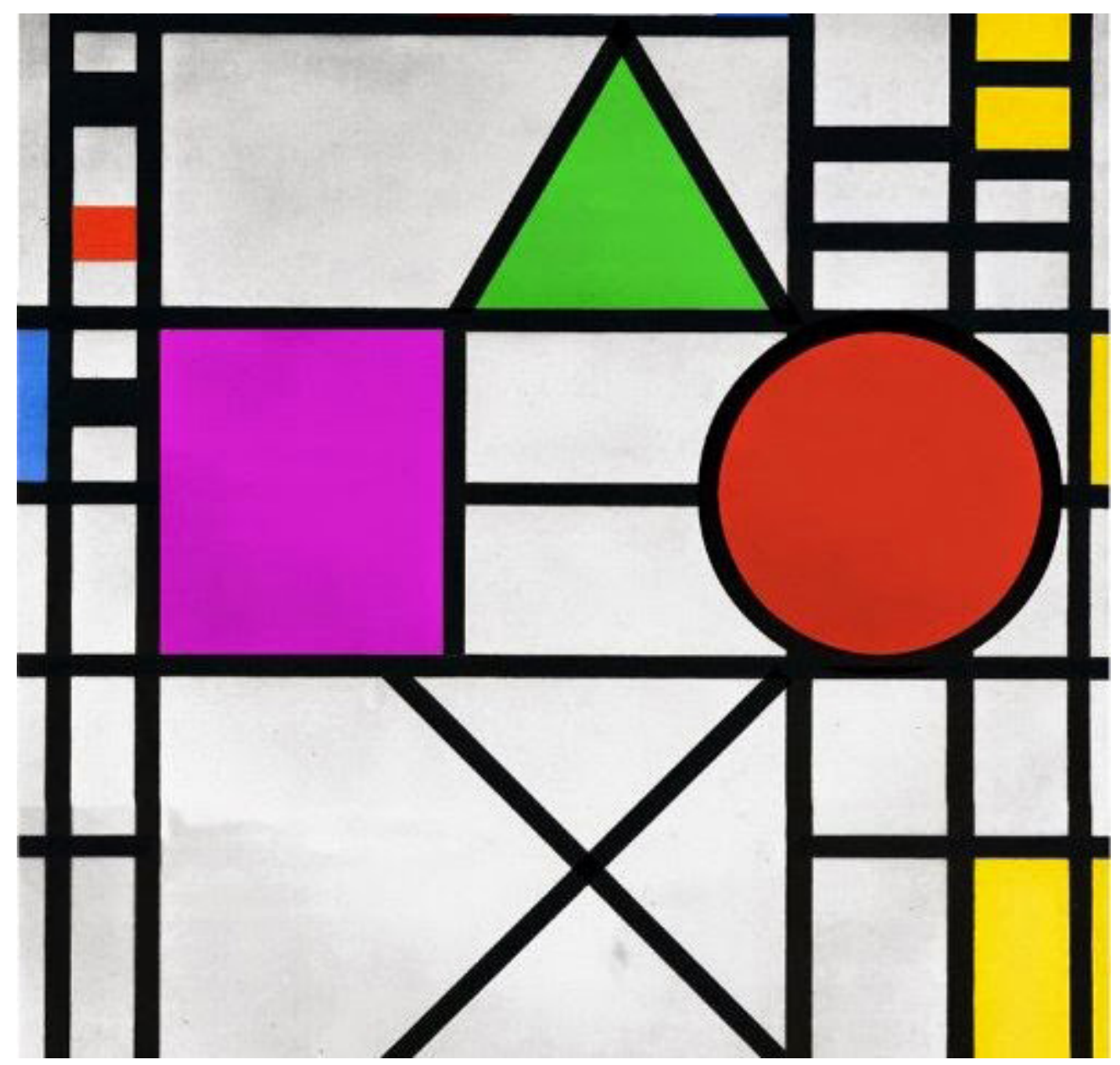

Figura 3: Mondrian - Composição, 1931.

Esta e outras obras, como Broadway Boogie Woogie, Composição em azul, cinzento e cor de rosa, de 1913, e as diversas Composições em azul, vermelho e amarelo, como a de 1921, por exemplo, permitiram a produção de duas outras exposições: uma, a das colchas de retalhos produzidas pelas costureiras do bairro, como artistas dos quadrados e outra, pelas próprias crianças, intitulada Dança dos quadrados, como forma de leitura das figuras geométricas que estudaram nos diferentes contextos citados: 


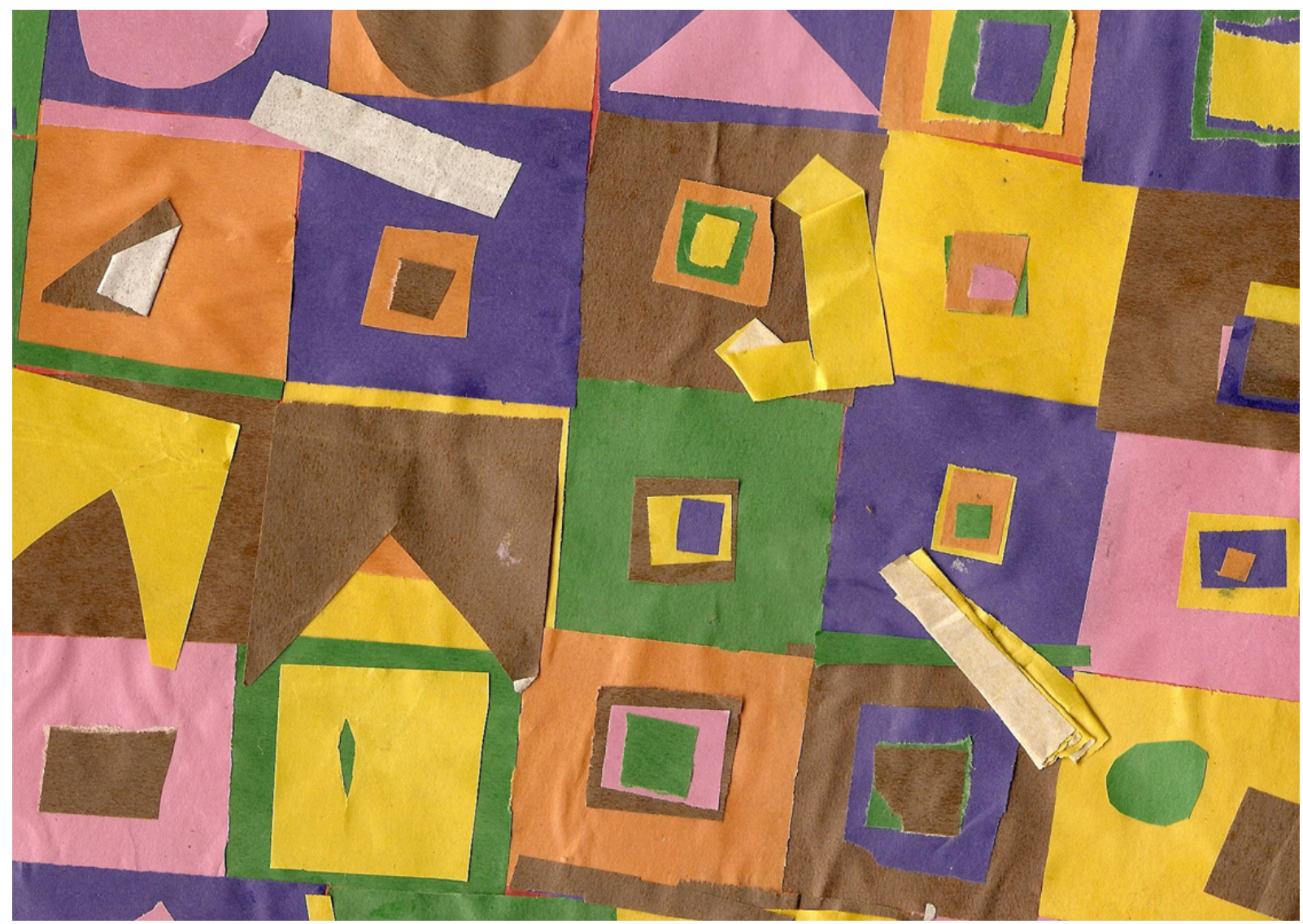

Figura 4: Obra componente da exposição Dança dos quadrados (4ํano, 2010).

Nesse percurso, ocorreu de Édylla trazer para uma das reuniões em roda uma imagem, atribuindo autoria a Mondrian:

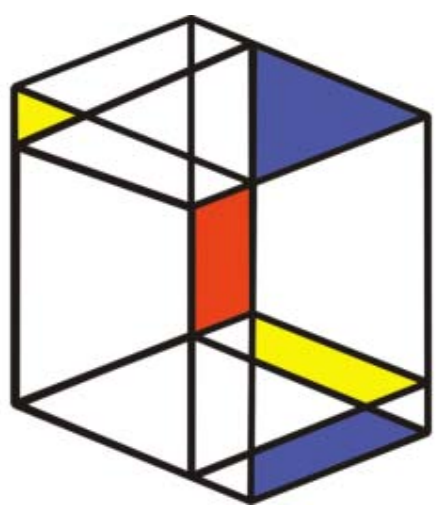

À época, a autoria não foi confirmada, mas foram discutidos rastros que possivelmente conduziram a criança a atribuí-la a Mondrian ${ }^{13}$ :

Figura 5: Imagem atribuída a Mondrian por Édylla

"Aqui tem as formas: quadrados, triângulos, trapézios um losango" [designando cada nomenclatura a uma parcela da imagem].

Professora: "E por que você acha que essa obra é do Mondrian?"

"Eu não sei. Minha mãe me ajudou. Achei que era dele porque tem formas que nem a gente estudou...”

13 Imagem recuperada em 26 de maio de 2015 de http://agal-gz.org/blogues/index.php/intra/2006/o6/27/o_ dia_que_piet_mondrian_desenhou_um_par 
Isabella: "É dele sim, prô! Nessa foto tem as mesmas cores de todas que a gente procurou, quando ele começou a desenhar as formas!"

Matheus: "São as cores primárias! A professora de artes ensinou. São o azul, o amarelo e o vermelho. E o Mondrian usou essas para inventar mais cores depois!"

Danty (concordando): "É mesmo!"

Aline: "Nessa tem uma forma aí que Édylla não disse!"

Professora: "É? E qual é?"

Aline se levanta da roda, puxa sua cadeira consigo, posiciona-se em frente à projeção da imagem e contorna a forma tridimensional com o dedo:

“Olha aqui! É essa forma!”

Émerson: "Eu não estou vendo nada!"

Aline repete a tentativa, até que Ryan se engaja no ofício de auxiliá-la. Toma um giz e registra os movimentos que a colega encenava com o dedo. Qual não foi o espanto da turma ao ver no registro uma figura tridimensional! Ao nomear a imagem produzida, Ryan usou o termo caixa. Esse termo tornou-se fonte de mal-entendido, tendo em vista que produziu discussões diversas, abarcando novas pesquisas, que constituíram nova orientação ao percurso de problematização da turma: investigar contextos em que caixas são usadas, além das nomenclaturas formais e usuais. Neste caso, a investigação se deu no sentido de percorrer diferentes práticas socioculturais, em que o termo caixa assume distintas significações: práticas de estocagem e como se desenrolam em diferentes situações contextuais, a exemplo dos pais que trabalhavam no contexto logístico; formas de acomodar mercadorias de acordo com tipos e especificações, nos baús dos caminhões; cuidados ao longo do transporte; diferentes formas de acomodações, o que nos conduziu à visita da planta de uma das fábricas em que trabalhavam, para conhecer modos de estocagem diversos. Outras práticas problematizadas foram filmográficas, literárias, teatrais, memorialísticas, desportivas; dança, arquivamento, entretenimento, dentre outras, nas quais a caixa participava.

Outro aspecto possibilitado pela narrativa que criaram para a obra de Mondrian foi o de deslocamento imagético da produção do artista para diferentes campos de atividades, o que pode ser observado em algumas das imagens que compuseram uma das coletâneas da turma: 


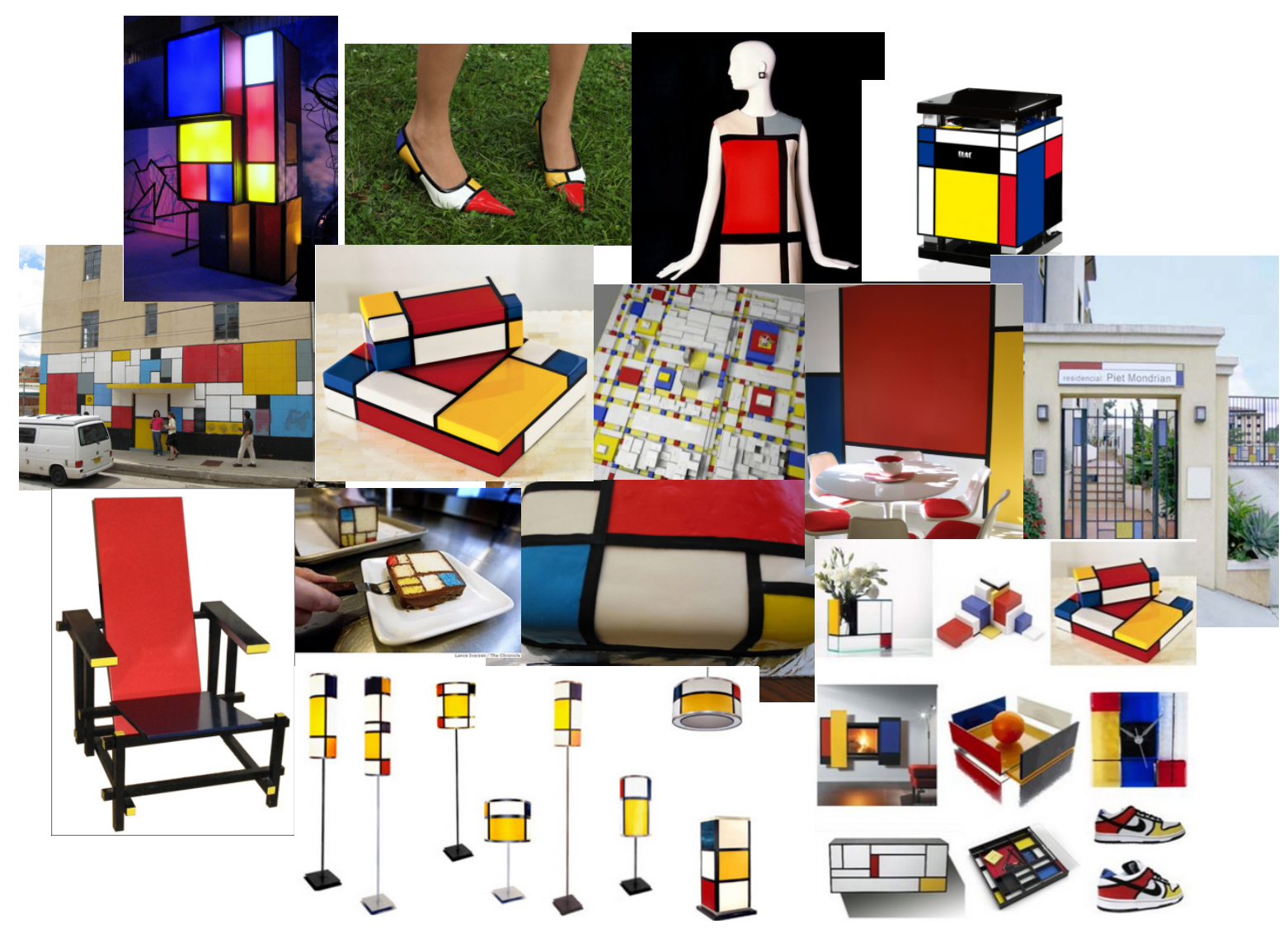

Figura 6: Mosaico de imagens da coletânea Mondrian (4ํano, 2010).

Essas formas de ação possibilitaram o envolvimento performático das crianças, inclusive no sentido da performance art, especialmente no modo mobilizado por Marina Abramovic (2015), em que a produção artística, muitas vezes é imaterial, num espaço em que a visão possa ser movediça, sem embates de paredes, como na performance Terra Comunal. Então, "uma linha é a trilha deixada pelo ponto em movimento... Ela é criada pelo movimento - mais especificamente, pela destruição do repouso, intenso e ensimesmado do ponto" ${ }^{14}$.

\section{Tombé de improviso: Considerações provisórias}

A problematização gramatical terapêutica indisciplinar permitiu conhecer percursos, problematizar práticas artísticas e matemáticas diversas, presentes em diferentes práticas socioculturais, possibilitando às crianças construir uma narrativa para a obra de Mondrian, bem como ver semelhanças de família entre essa narrativa, percursos em geometria e as obras desse artista, além de outros, como Marcone Moreira, Marina Leal, Sol Lewitt, Beatriz Milhazes, Gonçalo Ivo, Paulus Gerdes, Picasso e Julian Beever.

14 Frase atribuída a Wassily Kandinsky (citado em Seabra, 2015, p.o1). 
Nisto estaria o empreendimento de uma investigação gramatical, que tratou os diferentes tipos de conhecimentos em jogos de linguagem que proporcionam condições de existência das coisas. Por isso, geometria da química, da física, das ciências da natureza, do espaço plano ou esférico, da dança do ventre, das danças dos quadrados, das linhas, das caixas, danças folclóricas, clássica, ritual, de rua, de roda, que instrumentalizam o espaço de diferentes formas e constituem gramáticas de suas existências com diferentes problemas a resolver e com propósitos diversos, produzindo visão sinotípica dos modos "como as pessoas dizem o mundo e o que nele existe" (Crespo, pp. 100-101) e se dão a existir.

Dessa maneira, práticas como cálculo, quantificação, relações aplicadas a símbolos, tratamento de informação, interpretação e solução de problemas, testes de hipóteses, agrupamentos, análises, estudos de graus de segurança de ocorrência de eventos, relações espaço-temporais, bem como apreciações estéticas, gerenciamento e governamentalidade corporais, crítica, expressões corporais e de percepções, improvisações, composições, produção material, processos de criação, relações simbólicas e de fruição estética com objetos, formas, luz, movimentos, ambientes, imaginação, curiosidades, comunicação, acolhimento do outro, estabelecimento de relações de semelhanças e diferenças, formas expressivas e construtivas de materiais, também se deram no percurso vivenciado e compuseram uma forma de ver - a das crianças -, dentre ilimitadas outras possíveis.

Assim, um determinado contexto cultural expressará, por meio das regras das ações nele empreendidas, o que pode ou não ser entendido como arte e/ou matemática e pode ocorrer em quaisquer tempos e locais: desde propósitos de comunidades ditas primitivas que produziam inscrições no chão, organizações corporais, produções musicais para evocação de deuses ou fatos naturais - até mesmo para aquelas assumidas como modernas ou, ainda, pós-modernas, relacionadas à apreciação, ao design, à ambientação -, assumindo, assim, modos e processos próprios de significação, aproximados ou não dos modos racionais, lógicos e científicos de produção e sempre indicativos de relações de poder e/ou interesses.

Desse modo, julgamentos estéticos podem ser vistos nas práticas matemáticas, bem como o rigor em práticas artísticas, e tudo isso disperso nas práticas socioculturais. $\mathrm{O}$ que significa, portanto, estética em dispersão na vida, em estado civil. E, por esse modo de imaginar e praticar uma forma de ver, não buscamos a matematização da arte, mesmo considerando as indubitavelmente importantes transformações produzidas por práticas reunidas nos movimentos da matemática e da arte modernas, como revoluções das formas de compreensão dessas atividades, bem como relações com o cotidiano, a saber, performáticas.

Portanto, que a música e a coreografia se intensifiquem e o baile continue. Aquele $4^{\circ}$ ano prosseguiu em aprendizagens que ressoaram em alfabetização e letra- 
mentos de crianças que cursavam o mesmo ano/série pela segunda ou terceira vez. E muito mais! "E é altamente compreensível por que é que, no fim, tudo se torne poesia" (Wittgenstein, citado em Crespo, 2008, p. 280.), qual seja: a dança e a alma que desejou Drummond (Andrade, 2011).

\section{Referências}

Abramovic, Marina. (2015). Terra comunal. Recuperado em 20 de outubro de 2015, de http://terracomunal.sescsp.org.br/

Andrade, C. D. de. (2011). Isso é aquilo. Recuperado em 30 de maio de 2015, de https:// www.sites.google.com/site/portalpaideiadeliteratura/home/isso--aquilo-carlos-drummond-de-andrade

Andrade, C. D. de. (2012). Lição de coisas. São Paulo: Companhia das Letras.

Bencini, R. (2002). A arte explica a vida. Entrevista com Mirian Celeste Martins. Nova Escola. Recuperado em 15 de abril de 2015, de http://revistaescola.abril.com.br/ arte/fundamentos/arte-explica-vida-426395.shtml

Bogéa, Inês (Dir.). (2012). Figuras da dança Brasil [filme-vídeo]. (32 min, documentário). São Paulo: Companhia de Dança.

Brasil. (1997). Secretaria de Educação Fundamental. Parâmetros curriculares nacionais: matemática. Brasília: MEC/SEF.

Butler, J. (1994). Gender as performance: An interview with Judith Butler. Radical Philosophy, 67. Recuperado em 9 de abril de 2015, de http://www.theory.org.uk/ but-int 1.htm.

Chervel, A. (1990). História das disciplinas escolares: reflexões sobre um campo de pesquisa. Teoria e Educação, (2), 177-229.

Chervel, A. (1997). La culture scolaire - une approche historique. Belin: Paris.

Colker, D. (2006, 15 a 15 a 21 de dezembro). Dínamo. Folha de São Paulo; Guia da Folha, pp. 72-73.

Crespo, N. (2008). Imagem, percepção e expressão - A estética em Wittgenstein. Tese de Doutorado, Faculdade de Ciências Sociais e Humanas da Universidade de Lisboa $9,341$.

Cunha, J. G. M. da. (2009). Estudo sobre algumas notas de Wittgenstein. Estudos Filosóficos, (2), 1-27. Recuperado em 18 de abril de 2015, de http://www.ufsj.edu.br/ revistaestudosfilosoficos

Derrida, J. (2004). Gramatologia. São Paulo: Perspectiva, 2004.

Heaton, J. M. (2010). The talking cure: Wittgenstein's therapeutic method for psychotherapy. Hampshire: Palgrave Macmillan.

Jesus, F. R. de. (2015). Indisciplina e transgressão na escola. Tese de Doutorado, Faculdade de Educação, Unicamp, Campinas, 7, 512.

Luft, L. (2005). Pensar é transgredir. Rio de Janeiro: Record. 
McDonald, C. V. (1982, Summer). Choreographies. Entrevista com Jacques Derrida. Diacritics, 12 (2), 66-76.Cherchez la Femme Feminist Critique/Feminine Text.

McDonald, H. (2001). Narrative theory and cultural studies. Telos Journal, (121), 11-53.

Meireles, C. (1990). Ou isto ou aquilo. Rio de Janeiro: Nova Fronteira.

Miguel, A. (2010). Percursos indisciplinares na atividade de pesquisa em História (da Educação Matemática): entre jogos discursivos como práticas e práticas como jogos discursivos. Bolema, 23(35a). Recuperado em 15 de abril de 2015, de http://www. rc.unesp.br/igce/matematica/bolema.

Miguel, A., \& Vilela, D. S. (2008). Práticas escolares de mobilização de cultura matemática. Cadernos CEDES, 28(74), 97-120.

Miguel, A., Vilela, D. S., \& Moura, A. R. L. (2010). Desconstruindo a matemática escolar sob uma perspectiva pós-metafísica de educação. Zetetiké, (18), 129-206.

Moita Lopes, L. P. (2006). Por uma linguística aplicada indisciplinar. São Paulo: Parábola.

Mondrian, P. (1930). Azul, vermelho e amarelo (Reprodução). Acervo particular.

Mondrian, P. (1931). Composição. (Reprodução). Acervo particular.

Pennycook, A. (2006). Uma linguística aplicada transgressiva. In L. P. da Moita

Lopes (Org.), Por uma linguística aplicada indisciplinar (pp. 67-84). São Paulo: Parábola.

Read, A. (1995). Theatre and everyday life - An ethics of performance. London: Routledge.

Saint-Exupéry, A. de. (1989). O pequeno príncipe. São Paulo: Círculo do Livro.

Santoro, A., \& Sartorelli, A. V. (2008, julho). Os Vedas: um livro aberto. Superinteressante. Edição 254a. São Paulo: Abril.

Seabra, L. (2015). Desenvolvendo outra possibilidade de geração de imagens digitais: a rede social digital como ferramenta na criação de estamparia digital. Redige, (11), 132-142. Recuperado em 20 de outubro de 2015, de http://www2.cetiqt.senai.br/ ead/redige/index.php/redige/article/viewFile/61/144

Silva, Everson M. A. (2005). Arte como conhecimento: as concepções de ensino de arte na formação continuada dos professores dos anos iniciais do Ensino Fundamental de Recife. Dissertação de Mestrado, Universidade Federal de Pernambuco, Recife.

Silva, M. B., \& Galvão, A. M. de O. (2009). Concepções de arte na educação. HISTEDBR On-line, (35), 141-159.

Vilela, D. S. (2013). Usos e jogos de linguagem na matemática: Diálogo entre filosofia e educação matemática. São Paulo: Livraria da Física

Wittgenstein, L. (1980). Culture and value. Chicago: University of Chicago Press.

Wittgenstein, L. (2009). Investigações filosóficas. Rio de Janeiro: Vozes.

Zimmer, H. (1998). Mitos e símbolos na arte e civilização da Índia. São Paulo: Pallas. 


\section{Legislação}

Lei de Diretrizes e Bases para o Ensino de 1e e 2araus. №. 5.692. (1971). Brasília: Ministério da Educação e da Cultura.

Lei de Diretrizes e Bases da Educação Nacional: no 9394/96. (1996). Brasília: Senado Federal.

Parecer do Conselho Nacional de Educação à Federação de Arte-Educadores do BrasilFAEB. Distrito Federal. Processo n. 23001.000167/2005-89, Parecer CNE/CEB n. 22.

Submetido em: 26/05/2015

Aprovado em: 16/09/2015 